\title{
Pheochromocytoma Presenting As Acute Myocardial Infarction
}

\author{
N. Jayaprasad, Suresh Madhavan
}

Department of cardiology, Government Medical College, Kottayam, Kerala, India

Corresponding author, N.Jayaprasad,

Department of cardiology, Govt Medical College, Kottayam, Kerala, India, E-mail address- jayaprasadn@gmail.com

\begin{abstract}
Pheochromocytomas are rare neuro-endocrine tumors arising from chromaffin cells of the sympathetic nervous system.Pheochromocytomacan have diverse clinical presentations, which makes the diagnosis often difficult. We present a case of adrenalpheochromocytoma presenting as acute ST elevation myocardial infarction (STEMI). Catecholamine surge in patients with pheochromocytoma can cause myocardial infarction in the absence of atherosclerotic coronary artery disease. Pheochromocytoma presenting as acute myocardial infarction is very rare and it occurs in young individuals. This is a rare case report of pheochromocytoma in an elderly male presenting with acute STEMI successfully treated by resection of tumor.
\end{abstract}

Key words: pheochromocytoma, myocardial infarction, catecholamines, hypertension

\section{Case Report}

A 62 year old farmer presented with severe epigastric discomfort, vomiting and profuse sweating. He was hypertensive and diabetic since last four years poorly compliant on treatment. His blood pressure was 190/110 $\mathrm{mmHg}$ and heart rate was 60 beats per minute. Precordial examination was unremarkable except for a loud fourth heart sound. Initial ECG showed tall peaked T waves in precordial leads suggesting hyperacute changes of myocardial infarction. Subsequent ECGs showed loss of $\mathrm{R}$ waves with coved ST elevation and $\mathrm{T}$ wave inversion in leads V2,V3 and V4. Leads I,II,III,aVF, V5 and V6 showed $\mathrm{T}$ wave inversions (Fig 1 ). His echocardiogram showed severe hypokinesia of apical interventricular septum and apex with normal left ventricular systolic function.He was subjected to an immediate coronary angiogram with intention for primary percutaneous revascularization. Surprisingly his diagnostic coronary angiogram showed normal epicardial coronary arteries and no evidence of atherosclerosis (Fig 2).So he was treated conservatively with antiplatelet agents, nitroglycerine and statins.In his subsequent ECG sprecordial ST segment returned to baseline with deep $\mathrm{T}$ wave inversions, typical of serial evolutionary changes of STEMI. Cardiac enzymes were elevated, serum troponin I of $9 \mathrm{ng} / \mathrm{ml}$, (normal cut off is less than $0.05 \mathrm{ng} / \mathrm{ml}$ ).During the hospital stay he developed recurrent episodes of similar but less intense episodes of abdominal discomfort and vomiting. His blood pressure increased to levels as high as $200 / 120 \mathrm{~mm}$ of $\mathrm{Hg}$ during the episodes along with sinus tachycardia. This prompted us to suspect an alternative diagnosis in this case. His thyroid function tests were normal. In view of the labile hypertensive changes, we also considered the possibility of pheochromocytoma and proceed with an ultra sonogram of the abdomen which showed a mass in the region of right suprarenal gland. $24 \mathrm{hr}$ urine metanephrine levels were elevated (14.5 mg, normal value $<1 \mathrm{mg} / 24 \mathrm{hrs}$ ). A contrast enhanced CT scan of abdomen showed right suprarenal mass which was a well encapsulated with a fluid level(Fig 3). Both kidneys and left suprarenal gland were normal. Thus we arrived at a diagnosis of pheochromocytoma and the acute myocardial infarction was probably due to sympathetic surge. He was started on prazosin which controlled the blood pressure and his symptoms got ameliorated. Echocardiogram after one week showed no regional wall motion abnormality. Subsequently he underwent excision of the mass. There was wide BP fluctuations during surgery. A large cystic right suprarenal mass with multiple areas of hemorrhage was noted during the surgery. Left suprarenal gland was normal. Histopathology showed sheets of chromaffin cells consistent with pheochromocytoma and multiple areas of hemorrhage and necrosis (Fig 4). Patient is asymptomatic during follow up and is doing well. 

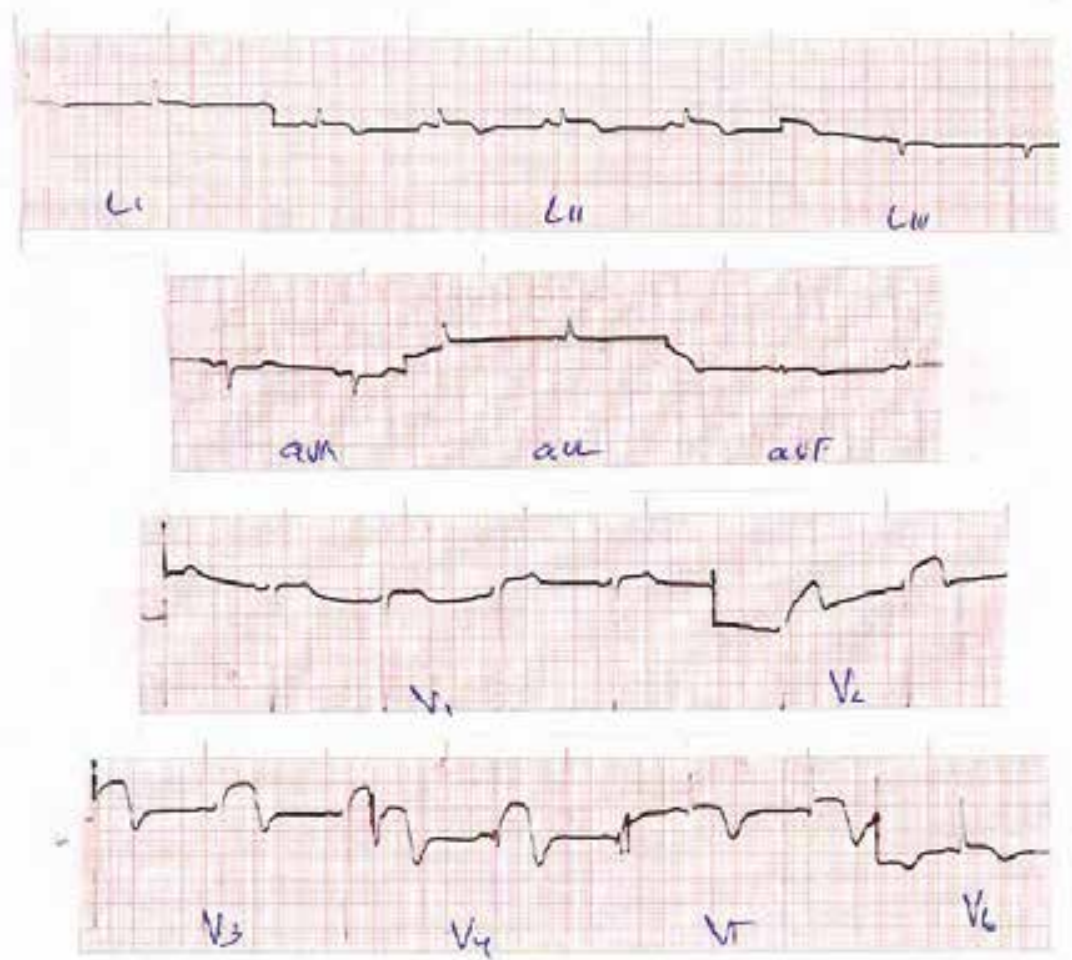

Fig 1: 12 lead ECG showing loss of R waves with coved ST elevation and T wave inversion in leads V2, V3 and V4. T wave is inverted in leads I,II,III,aVF, V5 and V6.

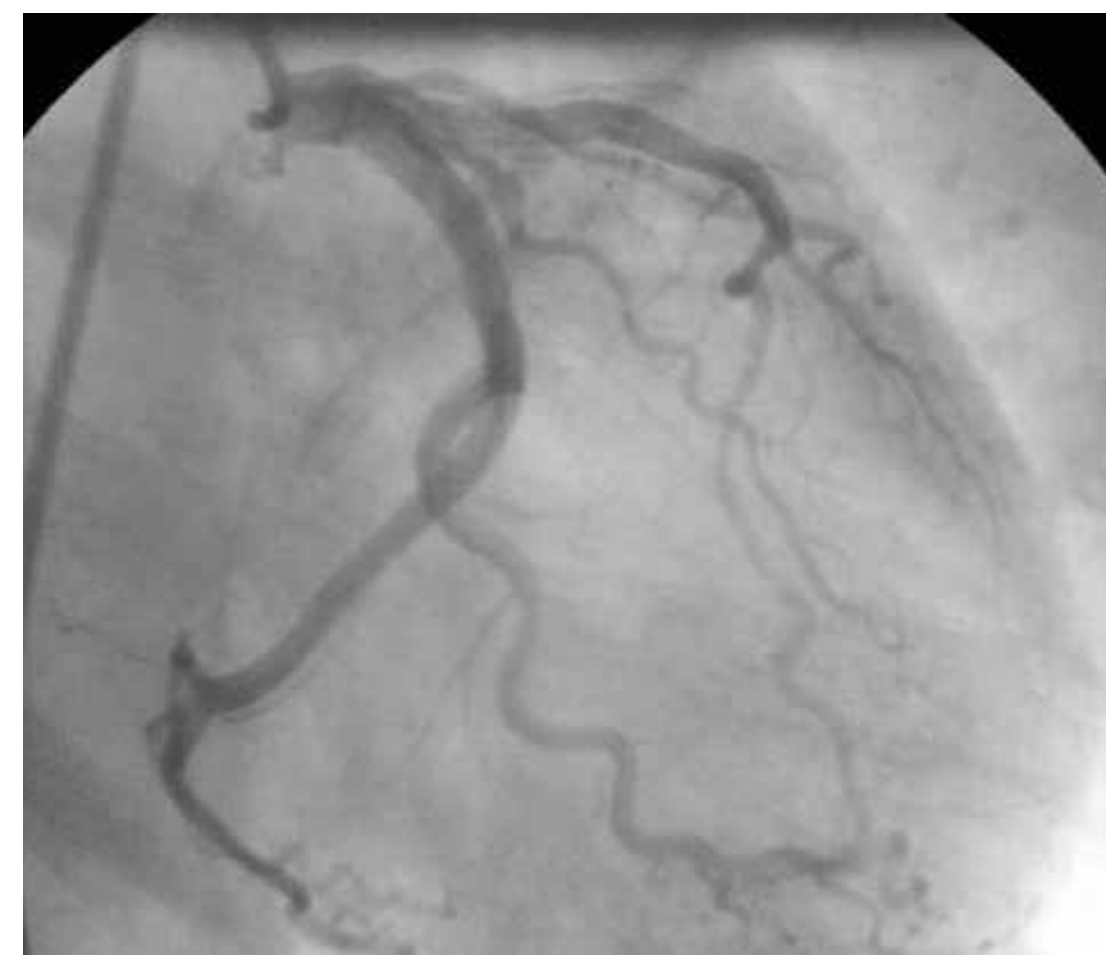

Fig 2: Coronary angiogram RAO caudal view showing normal left coronary artery and its branches. 


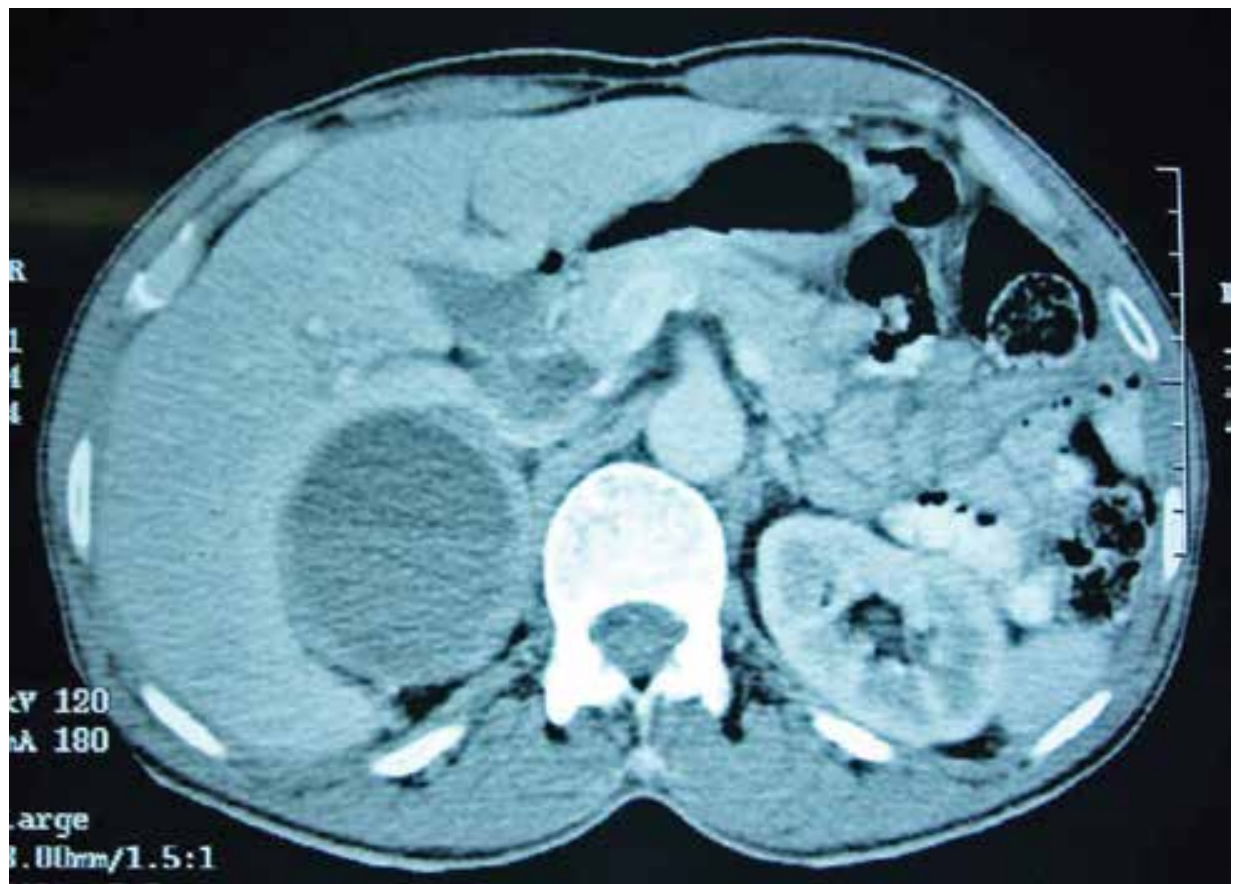

Fig 3: Contrast enhanced CT scan of abdomen showing a well encapsulated mass with a fluid level in the region of right suprarenal gland.

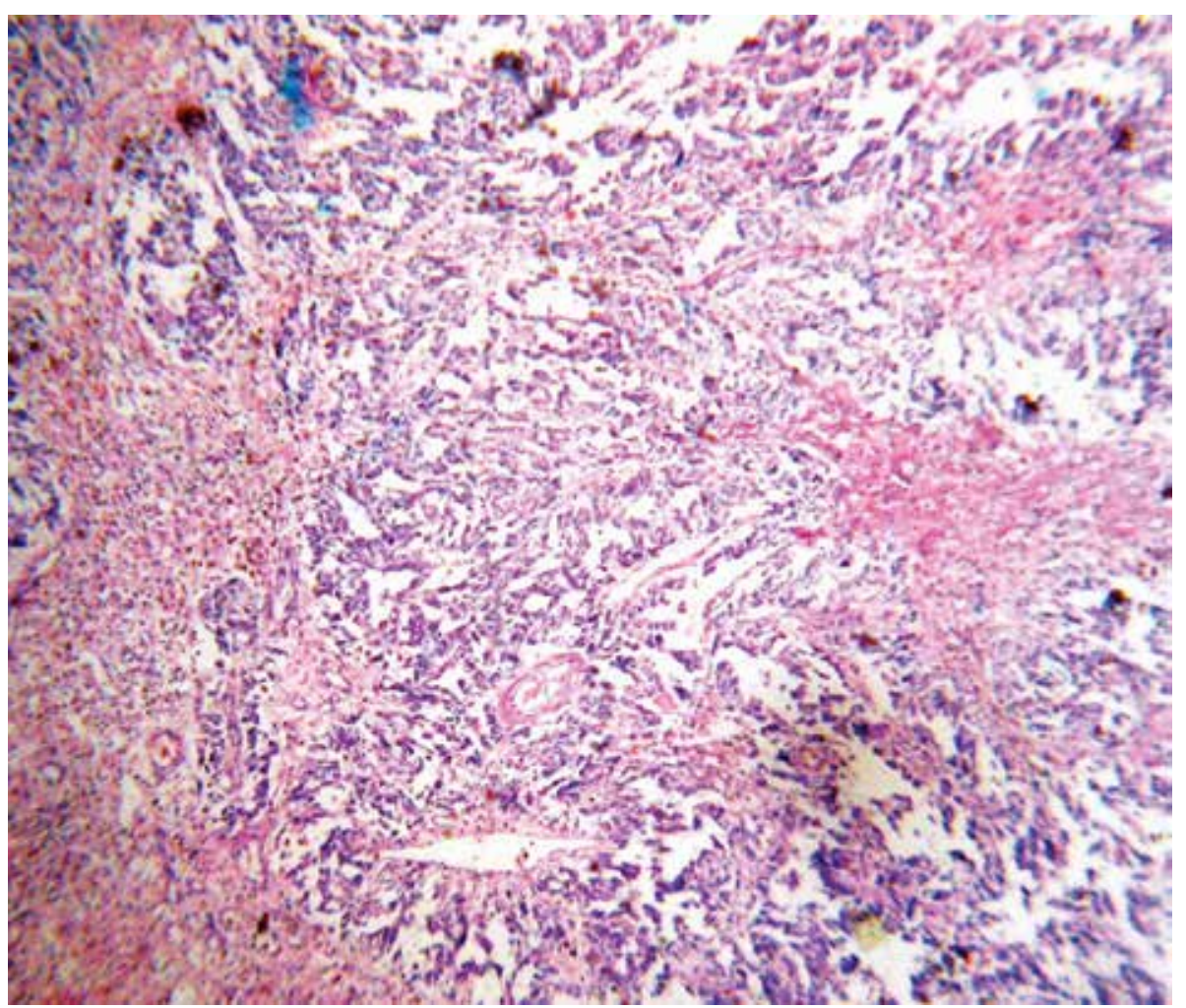

Fig 4: Histopathology showing sheets of chromaffin cells with multiple areas of hemorrhage and necrosis. 


\section{Discussion}

Pheochromocytomas most commonly arise from the adrenal gland (90\%) and are benign in $90 \%$ of cases. ${ }^{1}$ They produce characteristic systemic manifestations due to secretion of catecholamines, most commonly norepinephrine. Extra adrenal pheochromocytomas are more likely to be malignant (30\%). ${ }^{1}$ Cardiac manifestations of pheochromocytoma include hypertension, myocardial hypertrophy, myocarditis, cardiomyopathy, pulmonary edema,cardiogenic shock, arrhythmias and rarely myocardial infarction. ${ }^{2,3}$ Hypertension is the most frequent $(>70 \%)$ cardiovascular manifestation of pheochromocytoma. Hypertension is paroxysmal only in $50 \%$ of the cases and is persistent in the rest which makes diagnosis difficult. ${ }^{4}$

Pheochromocytomas have been rarely associated with acute myocardial infarction. Most of these cases have normal coronaries. ${ }^{2}$ The mechanism of myocardial infarction or segmental myocardial dysfunction associated with pheochromocytoma has been linked to coronary spasm or a direct toxic effect induced by catecholamines. ${ }^{5}$ Catecholamines increase left ventricular work by inducing left ventricular hypertrophy from hypertension and increase in heart rate. Changes in the coronary arteries include thickening of media potentially impairing blood flow to myocardium and coronary vasospasm. ${ }^{6}$ Catecholamines can cause cardiac myocyte apoptosis. ${ }^{7}$ Prolonged vasospasm can induce endothelial injury and promote platelet aggregation. The myocardial stunning like phenomenon during pheochromocytoma crisis has also been reported. The myocardial regional wall motion abnormality is often reversible as in our case. Anti-ischemic therapy with $\boldsymbol{\beta}$-blockers can be detrimental before establishing $\boldsymbol{\alpha}$-receptor blockade in these patients. In our case $\boldsymbol{\beta}$-blocker was not initially given due to initial presentation with low heart rate which was transient.

Angiography carries high-risk in patients with pheochromocytoma as contrast media can precipitate hypertensive crisis or congestive heart failure due to catecholamine release from the adrenal medulla. ${ }^{8}$ Antihypertensive agents advised include nonselective adrenergic antagonists (labetalol), $\boldsymbol{\alpha}$-antagonists (phentolamine), or vasodilatory agents like nitroglycerine or sodium nitroprusside. Haemorrage into the tumour can precipitate catecholamine crisis and myocardial infarction. ${ }^{9}$ In our case also, hemorrhage into the mass might have precipitated the catecholamine surge accounting for the myocardial infarction.

\section{Summary}

This case illustrates an uncommon presentation of pheochromocytoma crisis presenting as acute ST elevation myocardial infarction in an elderly man. A normal coronary angiogram indicates that coronary vasospasm or direct myocardial toxicity is the mechanism. A high index of suspicion for pheochromocytoma is needed in such cases as it is a lethal but potentially curable disease.

\section{References}

1. O'Connor DT. The adrenal medulla, catecholamines, and phaeochromocytoma. In: Cecil RL, Goldman L, Ausiello DA, editors. Cecil's Textbook of Medicine. Philadelphia, PA: Saunders; 2003.1419-1424.

2. Lenders JW, Eisenhofer G, Mannelli M, et al. Phaeochromocytoma. Lancet 2005;366:665-675.

3. Schurmeyer TH, Engeroff B, Dralle H, et al. Cardiological effects of catecholamine-secreting tumours. Eur J ClinInvest1997;27:189-195.

4. Werbel SS, Ober KP. Pheochromocytoma: Update on diagnosis, localization and management. Med Clin North Am 1995;79:131-135.

5. Nanda AS, Feldman A, Liang CS. Acute reversal of pheochromocytoma-induced catecholamine cardiomyopathy. Clin.Cardiol 1995;18: 421-423.

6. Irwin Klein. Endocrine disorders and cardiovascular disease. In:,BonowRO,Mann DL, ZipesDP, Libby P, BraunwaldE eds.Braunwald's Heart disease: a textbook of cardiovascular medicine.9th ed. Elsevier Saunders Company 2012;1829-1843.

7. Communal C, Singh K, Pimentel DR,et al. Norepinephrine stimulates apoptosis in adult rat ventricular myocytes by activation of the _beta -adrenergic pathway. Circulation 1998; 98:13291334.

8. Klingler HC, Klingler PJ, Martin Jr JK, et al. Pheochromocytoma. Urology 2001;57:1025-1032.

9. Brown H, Goldberg PA, Selter JG, et al. Hemorrhagic Pheochromocytoma Associated with Systemic Corticosteroid Therapy and Presenting as Myocardial Infarction with Severe Hypertension. J ClinEndocrinolMetab2005;90:563-569.
Cite this article as: N. Jayaprasad, Suresh Madhavan. Pheochromocytoma presenting as Acute Myocardial Infarction. Nepalese Heart Journal 2015;12(2):89-92 